\title{
Malignant Duodenal Lesion - Duodenal Tumor Vs Pancreatic Tumor - Semiological Radioimaging Characteristics
}

\author{
Ana Magdalena Bratu ${ }^{1}$, Iulia Alecsandra Salcianu'², Bogdan Valeriu Popa ${ }^{3}$, Constantin \\ Zaharia $^{4}$, Gheorghe Iana ${ }^{5}$ and Daniel Alin Cristian ${ }^{6}$ \\ ${ }^{1}$ Lecturer, Department of Radiology and Medical Imaging, "Carol Davila" University of Medicine and Pharmacy, "Colţea" Clinical Hospital, Bucharest, \\ Romania \\ ${ }^{2}$ Assistant Professor, Department of Radiology and Medical Imaging, "Carol Davila" University of Medicine and Pharmacy, "Colţea" Clinical Hospital, \\ Bucharest, Romania \\ ${ }^{3}$ Associate professor, Department of Radiology and Medical Imaging, "Carol Davila" University of Medicine and Pharmacy, "Floreasca" Clinical \\ Emergency Hospital, Bucharest, Romania \\ ${ }^{4}$ Professor, Department of Radiology and Medical Imaging, "Carol Davila" University of Medicine and Pharmacy, "Coltea" Clinical Hospital, Bucharest, \\ Romania \\ ${ }^{5}$ Professor, Department of Radiology and Medical Imaging, "Carol Davila" University of Medicine and Pharmacy, "Floreasca" Clinical Emergency \\ Hospital, Bucharest, Romania \\ ${ }^{6}$ Associate Professor, Department of General Surgery, "Carol Davila" University of Medicine and Pharmacy, "Colțea" Clinical Hospital, Bucharest, \\ Romania
}

Received: January 11, 2017; Accepted: February 20, 2017; Published: March 7, 2017

*Corresponding author: Iulia Alecsandra Salcianu, PhD, Assistant professor, Department of Radiology and Medical Imaging, "Colţea" Clinical Hospital, "Carol Davila" University of Medicine and Pharmacy, 1 I.C. Brătianu Blvd, Bucharest, Romania, Tel: +40-766524703; E-mail: salcianu_iulia@yahoo.com

\begin{abstract}
Introduction: Duodenal neoplasms are relatively rare entity, most often being cases of duodenal invasion by malignant masses developed in the duodenopancreatic region. The malignant infiltration of duodenum can be made either by a primary malignant duodenal tumor, either by invasion of a neighborhood malignancies, the most common being pancreatic cancer. The differentiation between these two malignant entities is absolutely necessary for the type of treatment chosen.
\end{abstract}

Materials and methods: The paper comprises a retrospective study, which includes 147 patients admitted and treated in a period of 7 years, being analyzed the images and the examinations results performed during 2009-2015, which were confronted with surgery protocols, where applicable, or endoscopic explorations and histological examination results.

Results: In the study group, 25 had been diagnosed with primary duodenal adenocarcinomas and the rest were pancreatic adenocarcinomas which invaded the duodenum. In terms of radioimaging, were analyzed the localization of tumors on the duodenal segment, the presence and the characteristics of lacunas and stenoses, the dimension of duodenal wall infiltrated by the tumor, and also the modifications of bile ducts.

Conclusions: If endoscopy cannot be performed, radio-imaging exams remain the only methods that can guide the starting point of a malignant tumor in duodenopancreatic region. It is important to know whether the tumor has duodenal or pancreatic origin for establish therapeutic strategy, the survival rate being different.

Keywords: Primary duodenal tumors; Pancreatic tumor; Radioimaging semiological characteristics

\section{Abbreviations}

CT (computed tomography); D1 (Duodenal bulb); D2 (Descending part of duodenum); D3 (Horizontal part of duodenum), D4 (Ascending part of duodenum)

\section{Introduction}

In oncological pathology, duodenal neopla sms are relatively rare entity, most often being cases of duodenal invasion by malignant masses developed in the duodenopancreatic region.

The malignant infiltration of duodenum can be made either by a primary malignant duodenal tumor, either by invasion of a neighborhood malignancies, the most common being pancreatic cancer. The differentiation between these two malignant entities is absolutely necessary for the type of treatment chosen.

Both in primary duodenal malignant tumors, and in duodenal invasion, usually by pancreatic cancer, the most common histopathological form is the adenocarcinoma. The survival rate between the two types of malignancies is significantly different, which makes the pretreatment diagnosis to be particularly important for the oncologist / surgeon.

Jiang et al consider that radical resection of duodenal adenocarcinomas is the best therapeutic method, the survival at 5 years being $53.6 \%$ [1]. At the same time the duodenopancreatectomy is a complex procedure [2], which associates a relative higher risk of mortality and a 30-50 \% risk of postoperative complications. 
For patients who present a pancreatic tumor invasive only in duodenal wall, preoperative oncologic therapy makes survival rate to be on average 25.9 months in those who had a radical resection [3]. This is basically independent of patient age [4]. The contribution of endoscopy with biopsy in case of malignancies with duodenal localization/invasion does not allow, in most cases, a clear differentiation between the two types of cancer. This is where radio-imaging exam, complementary to endoscopy, may possibly settle the starting point of the duodenal tumor.

This paper tries to make a radio-imaging differentiation between primary duodenal tumor and duodenal invasion from pancreatic cancer. Although computed tomography apparently settles this problem, the analysis of radiological signs can help the radiologist in more precise orientation of diagnosis.

\section{Materials and methods}

The paper comprises a retrospective study, which includes patients admitted and treated in a period of 7 years. For the retrospective study were analyzed the images and the examinations results performed during 2009-2015, which were confronted with surgery protocols, where applicable, or endoscopic explorations and histological examination results.

a. The initial group of patients included a total of 587 cases selected from a total of 873 cases diagnosed with tumors in duodenopancreatic region. Of these 587 cases remaining after a first selection, only a part was included in this study based on the following criteria:The tumor to be malignant, histopathological confirmed from a biopsy performed endoscopic, during or after surgery

b. The malignant tumor, regardless of the primary localization, to involve at least one segment of the duodenum

c. The radio-imaging examinations before surgery to include at least a gastro-duodenal exam and a computed tomography

d. The radio-imaging exploration to confirm the duodenal wall invasion by at least one method, whether this duodenal involvement was later proved to be primary or secondary

e. Study group included only adenocarcinomas

The cases which were excluded were due to one of the following criteria:

a. The failure to confirm histologically or pathologically of the neoplastic character of tumor, or the absence of duodenal involvement

b. Incomplete radio-imaging exploration of the patient before surgery

c. No evidence of duodenal invasion at all exploration methods used for detection

d. Were not taken into consideration the cases of vaterian ampulloma e. Were excluded the cases that showed adenopathies or metastasis identified on computed tomography

Finally were studied a total of 147 cases, of which 25 were primary duodenal adenocarcinomas and the rest were pancreatic adenocarcinomas which invaded the duodenum.

\section{Results}

The patients studied had ages between 30 and 84 years. Of these $54.66 \%$, i.e. a total of 88 patients, were cases in the age groups 51-60 years and 41-50 years. In primary duodenal tumor group, $88 \%$ (22 patients) of the cases were patients in these age groups. In the group of patients with pancreatic neoplasia invading the duodenum, only $49.2 \%$ (60 patients) were affiliated in these age groups. It was noted the absence of primary duodenal tumors in patients over 70 years. In terms of gender most affected was the male gender in an overall percentage of $67.5 \%$. In terms of localization the distribution at the mainly affected segment of primary duodenal tumors is shown in table 1 and in group of patient with pancreatic neoplasms who invaded the duodenum is shown in the table 2.

From these first two tables can be seen that regardless of neoplasia, primary duodenal or pancreatic, most affected segment is descending duodenum in a percentage of $56 \%$ for primary duodenal tumor, and in a rate of $59 \%$ for pancreatic neoplasms. In terms of radio-imaging semiology were analyzed lacuna, stenosis, ulceration, changes of mucosal folds, duodenal wall thickness, and changes in bile ducts. The analysis of duodenal wall thickness and changes of bile ducts is identified by computerized tomography, or magnetic resonance imaging. However there were discussed given their role in the diagnosis and pretreatment staging of malignancies with duodenal localization.

Lacuna represent an endophytic tumor that at conventional radiological examination is revealed as a filling defect of duodenal lumen (Figure 1), and at computed tomography exam as a tissular tumor mass that partially occupies the digestive lumen; it presents size, contours, structure, and enhancement. Depending on the location of the tumor we considered that,

Table 1: Distribution of cases of duodenal tumors depending on the duodenal segment affected

\begin{tabular}{|c|c|c|c|c|c|}
\hline Localization & D1 & D2 & $\begin{array}{c}\text { Inferior } \\
\text { duodenal } \\
\text { flexure }\end{array}$ & D3 & D4 \\
\hline $\begin{array}{c}\text { Number of } \\
\text { cases }\end{array}$ & 0 & 14 & 2 & 7 & 2 \\
\hline
\end{tabular}

Table 2: Distribution of cases of pancreatic cancer invading the duodenum depending on the origin at a pancreatic segment

\begin{tabular}{|c|c|c|c|c|}
\hline Segment & $\begin{array}{c}\text { The head } \\
\text { of pancreas }\end{array}$ & $\begin{array}{c}\text { Uncinate } \\
\text { process of } \\
\text { pancreas }\end{array}$ & $\begin{array}{c}\text { The body of } \\
\text { pancreas }\end{array}$ & $\begin{array}{c}\text { The tail of } \\
\text { pancreas }\end{array}$ \\
\hline $\begin{array}{c}\text { Number of } \\
\text { cases }\end{array}$ & 72 & 17 & 29 & 4 \\
\hline
\end{tabular}


besides the four duodenal segments described anatomically, to consider the inferior duodenal flexure a separate location due to intimate relation with uncinate process of the pancreas, which is a separate part of the pancreas (Table 3). Lacuna is found in $48 \%$ of cases with primary duodenal tumors, and only $23.8 \%$ of cases with duodenal invasion from pancreatic cancer. It can be noticed that both in primary duodenal tumors and pancreatic tumors invasive in the duodenum, the largest lacunas are found in descending duodenum (Figure 2), with a rate of $58.3 \%$ in primary duodenal tumors and $79.3 \%$ in pancreatic tumors affecting the duodenum.

The presence of a lacuna in the third and fourth segment of the duodenum was seen only in primary duodenal tumors. The dimensional classification of lacunas took into account the following criteria, namely sizes: up to $2 \mathrm{~cm}, 2-4 \mathrm{~cm}$, and over 4 $\mathrm{cm}$. Distribution of the number of cases depending on the size of the lacunas determined the appearance of subgroups whose values are shown in table 4 . It can be seen that primary duodenal tumor had sizes of $2-4 \mathrm{~cm}$ only in a percentage of $16.6 \%$ of the cases, the remainder being either smaller or bigger in size, unlike pancreatic neoplasms which determined lacunas measuring 2-4 $\mathrm{cm}$ in a $62 \%$ of cases. Regarding the presence of lacunas, it has been studied also their contours, which were classified as regular, irregular, and polycyclic (Table 5) (Figure 3).

It can be seen that only in primary duodenal tumors, lacunas may present in $1 / 3$ of cases polycyclic contours, and regular
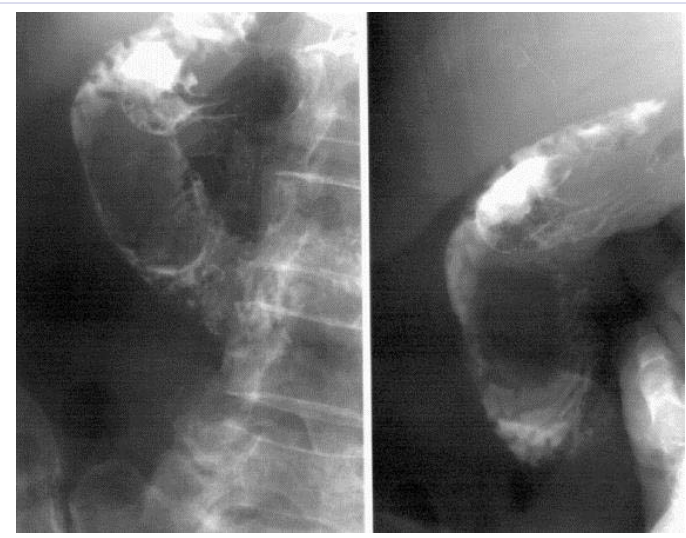

Figure 1: Conventional radiological examination which revealed a lacuna due to a primary duodenal tumor located in the D2 segment of duodenum

Table 3: Distribution of cases depending on the duodenal segment affected by the lacuna

\begin{tabular}{|c|c|r|r|r|r|}
\hline & \multicolumn{5}{|c|}{ Number of cases with lacuna } \\
\cline { 2 - 6 } Malignancy & D1 & D2 & $\begin{array}{c}\text { Inferior } \\
\text { duodenal } \\
\text { flexure }\end{array}$ & D3 & D4 \\
\hline $\begin{array}{c}\text { Primary } \\
\text { duodenal } \\
\text { tumors }\end{array}$ & 0 & 7 & 1 & 3 & 1 \\
\hline $\begin{array}{c}\text { Pancreatic } \\
\text { tumors }\end{array}$ & 0 & 23 & 6 & 0 & 0 \\
\hline
\end{tabular}

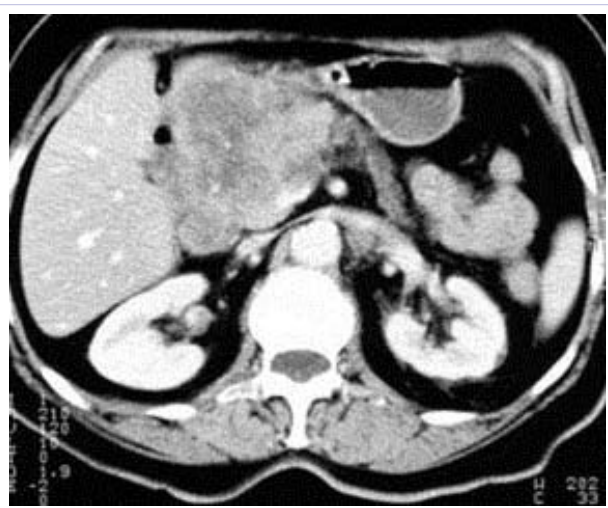

Figure 2: Abdominal CT scan which revealed a pancreatic tumor that causes a duodenal lacuna through duodenal invasion.

Table 4: Distribution of the number of cases depending on the size of lacuna

\begin{tabular}{|c|c|c|c|}
\hline \multirow{2}{*}{ Malignacy } & \multicolumn{3}{|c|}{ Size of lacuna } \\
\cline { 2 - 4 } & under $\mathbf{2} \mathbf{~ c m}$ & $\mathbf{2 - 4} \mathbf{~ c m}$ & over $\mathbf{4} \mathbf{~ c m}$ \\
\hline $\begin{array}{c}\text { Primary } \\
\text { duodenal tumors }\end{array}$ & 5 & 2 & 5 \\
\hline $\begin{array}{c}\text { Pancreatic } \\
\text { tumors }\end{array}$ & 6 & 18 & 5 \\
\hline
\end{tabular}

Table 5: Distribution of the number of cases with lacunas depending on its contours

\begin{tabular}{|c|c|c|c|}
\hline \multirow{2}{*}{ Malignancy } & \multicolumn{3}{|c|}{ Contour } \\
\cline { 2 - 4 } & Regular & Irregular & Polycyclic \\
\hline $\begin{array}{c}\text { Primary } \\
\text { duodenal } \\
\text { tumours }\end{array}$ & 0 & 8 & 4 \\
\hline $\begin{array}{c}\text { Pancreatic } \\
\text { tumours }\end{array}$ & 0 & 29 & 0 \\
\hline
\end{tabular}

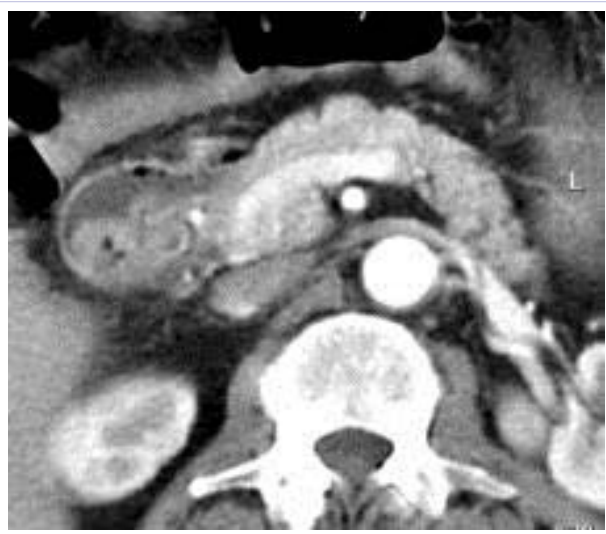

Figure 3: Abdominal CT scan which revealed a lacuna with polycyclic contours due to a primary duodenal tumor.

contours are excluded regardless of the type of cancer that cause a lacuna. Stenosis, from semiological point of view, represents parietal tumor infiltration, or peritumoral submucosal edema at the level of a lumen of digestive tract. This type of radio-imaging 
change was seen in $52 \%$ of cases of primary duodenal tumors, and in $26 \%$ of pancreatic tumors that have invaded the duodenum. To be identified either by conventional radiological methods, or by CT scanning, at least $50 \%$ of duodenal wall circumference must be impaired. In terms of localization of stenosis at a segment of duodenum, the distribution of cases is shown in the table 6 .

If in case of lacunas, pancreatic neoplasms do not cause them in the third and fourth portion of the duodenum, in case of stenosis, this may be present at those levels in pancreatic neoplasms with duodenal infiltration. But, as in lacunas, most affected duodenal segment by a stenosis is the second portion regardless the type of malignancy that caused it. As in lacunas, in the dimensional classification of stenosis we considered the following criteria, namely: a maximum of $2 \mathrm{~cm}$ in size, $2-4 \mathrm{~cm}$ and over $4 \mathrm{~cm}$. The number distribution of cases according to the stenosis size causes the appearance of subgroups whose value is shown in table 7. Unlike lacunas, stenosis in primary duodenal tumors have a length of up to $2 \mathrm{~cm}$ in a proportion of $53.8 \%$, and this length of stenosis in pancreatic neoplasia is found in $28.1 \%$ of cases, and those with sizes of $2-4 \mathrm{~cm}$ were found in $46.8 \%$ of cases (Figure 4,5).

The ulceration is a mucosal impairment in tumors that affect the duodenum, whether is primary or adjacency neoplasia (Figure 6). Ulcers due to their small sizes usually are not detectable on CT scanning. It turned out that the most reliable method of identify an ulcer is the double-contrast duodenography using a duodenal probe. In the present study ulcers were associated with stenoses or lacunas, being detected as a singular sign. Ulcers were found in a proportion of $30 \%$ for primary duodenal tumors and at a rate of $45 \%$ for pancreatic tumors that have invaded the duodenum, in the latter a proportion of $75 \%$ were found in descending duodenum, therefore determined by a cephalo-pancreatic cancer. The changes of mucosal folds, regardless of their type, represent a radiological sign extremely important, especially in primary duodenal tumors. Thus, changes in mucosal folds were

Table 6: Distribution of the number of cases with stenosis depending on affected segment of duodenum

\begin{tabular}{|l|c|c|c|c|c|}
\hline \multirow{2}{*}{ Malignancy } & \multicolumn{5}{|c|}{ Number of cases with stenosis } \\
\cline { 2 - 6 } & D1 & D2 $\begin{array}{l}\text { Inferior } \\
\text { duodenal } \\
\text { flexure }\end{array}$ & D3 & D4 \\
\hline $\begin{array}{l}\text { Primary duodenal } \\
\text { tumors }\end{array}$ & 0 & 7 & 1 & 4 & 1 \\
\hline Pancreatic tumors & 0 & 21 & 4 & 6 & 1 \\
\hline
\end{tabular}

Table 7: Distribution of the number of cases with stenosis depending on its size

\begin{tabular}{|l|c|c|c|}
\hline \multirow{2}{*}{ Malignancy } & \multicolumn{3}{|c|}{ Number of cases with stenosis } \\
\cline { 2 - 4 } & $\mathbf{2} \mathbf{~ c m}$ & $\mathbf{2 - 4} \mathbf{~ c m}$ & $\mathbf{4} \mathbf{~ c m}$ \\
\hline $\begin{array}{l}\text { Primary duoder } \\
\text { tumors }\end{array}$ & 7 & 4 & 2 \\
\hline Pancreatic tumors & 9 & 15 & 8 \\
\hline
\end{tabular}

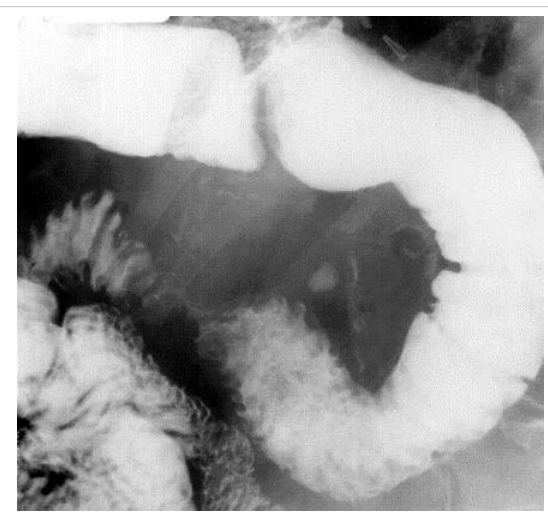

Figure 4: Conventional radiological examination which revealed a stenosis in the D4 segment of duodenum due to duodenal invasion from a pancreatic cancer.

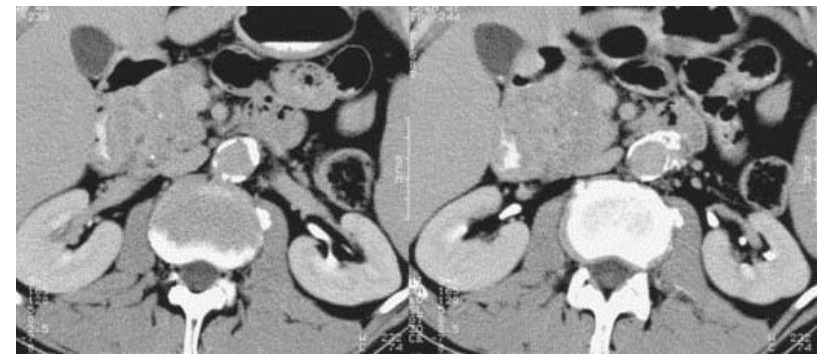

Figure 5: Abdominal CT scan which revealed a duodenal stenosis due to pancreatic cancer

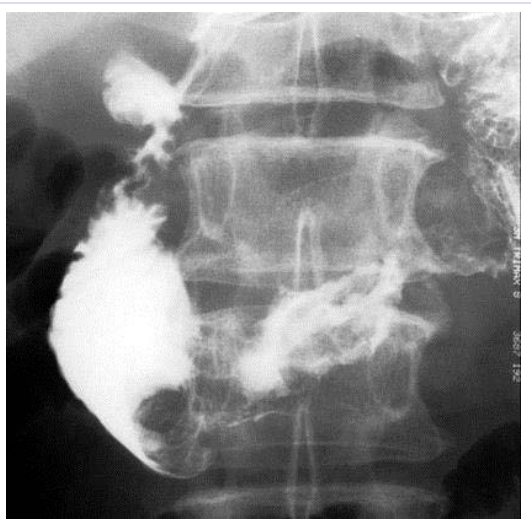

Figure 6: Conventional radiological examination which revealed a lacuna with ulceration due to a primary duodenal tumor.

identified in all 25 cases of primary cancer of the duodenum, the percentage being $100 \%$ (Figure 7). Out of the 122 cases of malignant tumors of pancreas with duodenal invasion were found changes in mucosal folds in 105 cases, which represent a proportion of $86 \%$. The percentage of impairment of duodenal mucosa in case of tumoral infiltration by a pancreatic neoplasm is substantial, but there are cases where the impairment was limited to the other parietal layers. From the changes of mucosal folds (effacement, distorted, enlarged, etc.), the appearance of a $\mathrm{T}$ shaped fold is considered by literature as pathognomonic for 
pancreatic neoplasms, but this was identified in a rate of only 4.8 $\%$ of cases of pancreatic cancers with duodenal invasion.

Interesting is the fact that, in primary duodenal tumor, from the 25 cases studied, 18 patients, which represents a percentage of $72 \%$, had changes in the mucosal folds extended to more than one duodenal segment. It was also observed that in duodenal tumors the most frequent modification encountered is the effacement of folds, found in 16 of the 25 cases studied, which represent $64 \%$ of cases, but which can be also determined by edematous infiltration from small lesions strictly localized to the mucosa. This change is actually a real destruction of mucosal relief by the tumor. In pancreatic neoplastic process, the duodenal mucosal injury is represented by a rate of $36.19 \%$ for detection of effaced folds, which associated with signs of parietal invasion suggest a vertical extension of neoplasia. In the case of pancreatic neoplasms was found disorganized folds with a higher frequency, the percentage being $27.62 \%$, and interrupted folds at a rate of $19.05 \%$.

In primary duodenal tumors disorganized folds are, as frequency of occurrence, in second place with a total of 13 cases $52 \%$, and interrupted folds were found in 12 cases, representing a rate of $48 \%$, this change being the direct result of the presence of tumor process which caused destruction of duodenal mucosa. Hypertrophic folds, mainly consecutive to neoplastic invasion both in longitudinal and circumferential way, were present in 10 cases of duodenal adenocarcinoma, representing a rate of $40 \%$. Is interesting that in the study group with duodenal neoplasms, 20 cases, i.e. $80 \%$ of patients, the changes of folds appearance were actually multiple, at least two types. Duodenal wall thickness is directly measurable at CT scanning or magnetic resonance imaging exam. Normal thickness of duodenum wall has the maximum size of $4 \mathrm{~mm}$. The detection of a thick duodenal wall was encountered in 21 cases with duodenal adenocarcinomas, which represents a high percentage- $84 \%$. In the present study, we have identified 51 cases of duodenal infiltration from pancreatic cancer which had duodenal parietal thickening. The cases with duodenal wall thickening were divided into three groups: between 4-8 $\mathrm{mm}, 8-10 \mathrm{~mm}$, and more than between 10 mm (Table 8).

It can be seen that most cases of primary duodenal tumors showed wall thickening over $10 \mathrm{~mm}$ (Figure 8), in a proportion of $48 \%$, second in frequency being cases with a parietal thickening between 8 and $10 \mathrm{~mm}$, the percentage being $36 \%$, and only a few cases being those with wall thickening between 4 and $8 \mathrm{~mm}$, only $16 \%$ of cases. Of the 25 cases of primary duodenal tumors, 21 cases (representing $84 \%$ ) had malignancies that determined duodenal wall thickening more than $8 \mathrm{~mm}$.

From the results it can be seen that a rate of $26.23 \%$ of duodenal infiltration due to pancreatic neoplasia showed minimal thickening of the duodenal wall, having dimensions of 4-8 $\mathrm{mm}$. The remaining cases presented an increased thickening of the wall, measuring 8-10 mm, the percentage being $15.57 \%$. In none of the cases was detected duodenal wall thickness greater
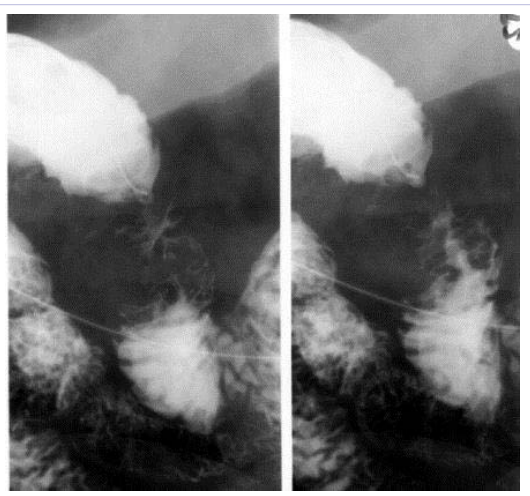

Figure 7: Conventional radiological examination which revealed modification in mucosal folds of duodenum due to a primary duodenal tumor.

Table 8: Distribution of the number of cases according to the duodenal wall thickness

\begin{tabular}{|c|c|c|c|}
\hline \multirow{2}{*}{ Malignancy } & \multicolumn{3}{|c|}{ Number of cases with thick duodenal wall } \\
\cline { 2 - 4 } & $\mathbf{4 - 8} \mathbf{~ m m}$ & $\mathbf{8 - 1 0} \mathbf{~ m m}$ & over 10 $\mathbf{~ m m}$ \\
\hline $\begin{array}{c}\text { Primary } \\
\text { duodenal tumors }\end{array}$ & 4 & 9 & 12 \\
\hline $\begin{array}{c}\text { Pancreatic } \\
\text { tumors }\end{array}$ & 32 & 19 & 0 \\
\hline
\end{tabular}

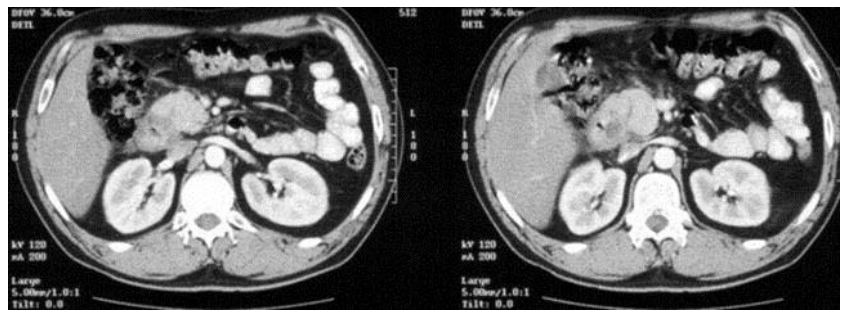

Figure 8: Abdominal CT scan which revealed a circumferential thickening of duodenal wall over $10 \mathrm{~mm}$.

than $10 \mathrm{~mm}$, unlike primary duodenal malignancies, in which the majority showed a thickened wall more than $10 \mathrm{~mm}$. This parietal thickening indicates duodenal invasion, especially in the absence of other radio-imaging signs that may suggest it.

Changes in the biliary tract were found in a small number in patients with primary duodenal tumors; only two cases showed a moderate dilatation of the common bile duct, whose size did not exceed $1.5 \mathrm{~cm}$. This number of cases who presented bile duct dilatation represents a percentage of only $8 \%$. Changes in the biliary ducts due to pancreatic cancer with duodenal invasion are directly linked to the anatomic direct relation of the bile ducts with the pancreas. It follows that impaired biliary tree can be found only in cephalo-pancreatic malignancies, with or without ampullary invasion (Figure 9).

Semiologically, changes in common bile duct may include dilation, narrowing, contour alterations, and displacements. The presence of gallstones is independent from the tumor. If in primary duodenal malignancy the biliary ducts changes 
manifested just by choledoch dilatation, in cephalo-pancreatic neoplasms were found also other changes. Out of 72 cases of cephalo-pancreatic cancers changes in the biliary tree were found in half of them (Table 9). Narrowing of the common bile duct, which is embedded in the tumor, causes dilation of the remaining choledoch. In cephalo-pancreatic tumors affecting the duodenum, the location of the tumor mass is mostly eccentric to axis of the duct, involving the papillary portion of the common bile duct. This is the cause for determining this big difference between detection of choledoch dilatation versus segmental narrowing, which was seen in a rate of only $19.45 \%$.

The displacement of biliary ducts, found in a rate of 16.66 $\%$, is also an argument for eccentric localization of cephalopancreatic cancer invading the duodenum.

\section{Discussion}

Although they are considered to be very rare, there are studies that have shown that primary duodenal tumors are found in 15$25 \%$ of cases of malignant tumors of the small intestine [5-7]. In the study group, primary duodenal malignant tumors were found in a number of 25 cases representing $17 \%$ of all malignancies studied; in terms of pathology were adenocarcinomas. Darrah and Nolan consider that among primary malignant duodenal tumors, the adenocarcinomas are the most common, representing $80-90 \%$ of cases, and are usually detected at an advanced stage, due to its non-specific clinical presentation [8,9]. In Bockus gastroenterology it is considered that duodenal adenocarcinoma accounts almost all duodenal malignancy [10].

In terms of affecting the duodenum from a tumor in the duodenopancreatic region, as frequency the first are malignant

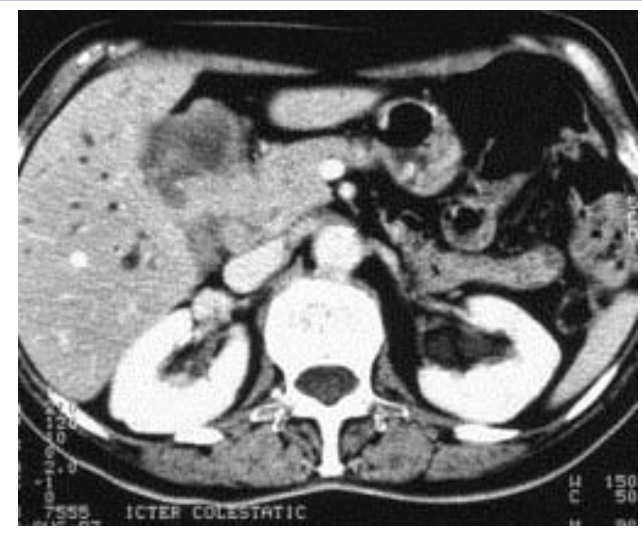

Figure 9: Abdominal CT scan which revealed modifications in biliary ducts (choledoch stenosis with biliary ducts dilatation) due to a pancreatic cancer that invades the duodenum.

Table 9: Distribution of cases of pancreatic neoplasms invading the duodenum depending on the type of change in biliary ducts

\begin{tabular}{|c|c|c|c|}
\hline $\begin{array}{c}\text { Modifications } \\
\text { of bile ducts }\end{array}$ & Dilatation & Narrowing & Displacement \\
\hline Number of cases & 23 & 7 & 6 \\
\hline
\end{tabular}

pancreatic tumors, represented by 122 cases, meaning $83 \%$ of all cases in the study group. In Harrison is presented that pancreatic cancer is one of the top 5 causes of death in the US, accounting about $10 \%$ of all malignancies with gastrointestinal location [11]. Lucas et al show that the mortality in pancreatic cancer increased between 1980 and 2013 worldwide [12]. Stephens studying the frequency of adenocarcinomas in pancreatic tumors establishes a rate of appearance of $85 \%$ [13].

Of all malignancies invading the duodenum, 72 cases (59\%) were cephalo-pancreatic neoplasms who invaded duodenum. Since the neoplasms in head of the pancreas are the most common cancers affecting the pancreas, it is explainable the high frequency of duodenal involvement in this condition. Yamaguchi and Enjoji following a study comprising 304 patients concluded that $80 \%$ of pancreatic cancers are in the head of the pancreas [14].

Uncinate process cancer is ranked in third place as frequency in damaging the duodenum, comprising 17 cases, representing $13.9 \%$ of pancreatic neoplasms invading into the duodenum. As frequency, on second place is the cancer located in the pancreas body, with 29 cases, i.e. $23.77 \%$. The duodenum is the least affected by pancreatic neoplasm in the tail in the study group being found only 4 cases, representing $3.27 \%$ of all pancreatic cancers. The frequency of impaired so different, depending of pancreatic segment involved, is explained by the relationship between the segments of the duodenum and those of the pancreas. The invasion in the duodenum makes the tumor being a T3 stage [15]. T3 stage pancreatic tumors may or may not be suitable for surgery, so in terms surgery they are borderline [16]. There are authors who said that duodenal invasion significantly reduces the survival rate in pancreatic neoplasms [17]. Unlike pancreatic cancer invading the duodenum, primary duodenal neoplasm benefits of radical surgical therapy and has more favorable outcomes compared to other periampullary malignancies and excision is considered the backbone of treatment for patients with localized tumors or limited metastatic disease when feasible $[18,19]$. Also, there are described situations where not even biopsy can differentiate with certainty the duodenal invasion by a pancreatic tumor or vice versa [20].

It can be observed that in the study group the first segment of the duodenum was not affected nor by the primary duodenal tumors nor by pancreatic neoplasms. There are some studies that stated that $92.6 \%$ of nonampullary duodenal adenocarcinomas affect the first two segments of the duodenum, but without making the difference between these two [21]. Maglinte et al. state that the location of choice for duodenal carcinoma, expressed by the lacuna, is the periampullary region, i.e. the descending duodenum, as all primary duodenal tumors [22].

Nolan considers that duodenal adenocarcinoma is the most frequently located on the descending duodenum and the third duodenal portion [23]. From the analysis of our study group emerges that the impaired of descending duodenum in primary duodenal tumors, expressed by a lacuna, approaching $60 \%$, while 
in pancreatic tumors with duodenal involvement reach a rate of nearly $80 \%$, making this radiological sign not to have a particular relevance in differentiation between the two neoplastic entities. Instead, the presence of lacunas in the third and fourth segment of the duodenum, although the number of cases is small, makes that its presence rather to lead to the diagnosis of primary duodenal tumor.

Ferruci believes, however, that lacuna is one of the radiological signs that may indicate the invasion of duodenum by a pancreatic adenocarcinoma, without making any reference to the percentage of detection of this type of radiological feature [24].

Stephens in a study on pancreatic adenocarcinoma concludes that it is the most common form of pancreatic cancer, the most aggressive, survival being no more than 2 years [13]. The same author believes that this form of neoplasia is actually a ductal adenocarcinoma, which causes rapid dissemination, in particular through contiguity, but also metastatic, regardless of tumor size.

Helmberger et al. state that ductal adenocarcinoma reaches a percentage of $85 \%-90 \%$ of all pancreatic malignancies [25].

If the diameters of lacunas are between 2 and $4 \mathrm{~cm}$ orient towards diagnosis of a pancreatic tumor that invaded duodenum. Helmberger et al. consider that due to the proximity with bile ducts and duodenum, cephalo-pancreatic neoplasia and the uncinate process tumors are discovered due to symptoms present, faster than the malignancies in the body or tail of the pancreas. The same authors believe that in ductal adenocarcinomas, although tumor size ranges between 1.5 and $10 \mathrm{~cm}$, they are discovered when ranging $3-5 \mathrm{~cm}$, being mainly higher on the body and tail of

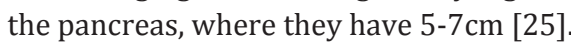

Of all the cases studied who presented lacunas, only $1 / 3$ of duodenal tumors showed polycyclic contours, and Darrah and Nolan consider that the presence of a lacuna with polypoid shape is pathognomonic for duodenal malignancy [8]. At this statement a study made by Bosse had a major contribution, and from which resulted a breviary of radiological semiology of primary duodenal tumors [26]. Moss considers that should not be forgotten the inflammatory reaction in the periphery of tumors, which causes irregular contours, which in the present study were found in $2 / 3$ of lacunas due to duodenal tumors, and in all lacunas determined by pancreatic neoplasms [27].

If the lacuna is considered by most literature as determined by primary duodenal tumor, the stenosis is considered the result of parietal invasion caused by pancreatic cancer, as stated by Ferruci [24]. Also, Kasum'ian et al. consider that stenosis is an elementary radiological change that is commonly found in pancreatic neoplasms infiltrating the duodenum, causing an obstructive syndrome, more or less expressed [28].

In primary duodenal tumors stenosis is found with similar ratio as the lacuna in relation to a duodenal segment affected, and in pancreatic neoplasia invading the duodenum stenosis unlike lacuna affected also the last two portions of the duodenum.
Withal, the overall percentage is very close to the one presented by lacunas. In primary duodenal neoplasms stenosis is found in $52 \%$ of the cases. This percentage indicates a double ratio of incidence of stenosis in primary malignant duodenal tumors, compared to malignant pancreatic tumors which invade the duodenum. It cannot be conclude that it is a specific radiological sign for primary duodenal neoplasia because this sign is also found in one quarter of pancreatic tumors infiltrating the duodenum.

In terms of size, stenoses with length over $4 \mathrm{~cm}$ were found in only $15.38 \%$ of cases of duodenal tumors, while in the cases with pancreatic cancers stenosis over $4 \mathrm{~cm}$ was found in a quarter of the cases. The significance of survival rate depending on the size of stenosis is controversial in the literature [29].

Unfortunately the folds changes are not helpful in determining the starting point of neoplasia, being found in most of the cases studied. In the present study a particular importance is given to duodenal wall thickness at the level of a tumor. If in primary duodenal tumor wall thickening proved to be a constant sign, with a ratio of occurrence of $100 \%$, in pancreatic tumors this was found only in $41.8 \%$ of cases. Loze et al. believe that in $90 \%$ of cases of duodenopancreatic tumors the duodenal wall is thickened. If we report the total number of cases who had thickened wall at the entire study group, it appears that only in a proportion of $51.7 \%$ of the duodenopancreatic tumors the duodenal wall was found thicker than normal [30]. Thus, in almost half of cases of primary duodenal tumors, the duodenal wall had thickness over $10 \mathrm{~mm}$, value which in pancreatic tumors invading the duodenum was not found. Instead, in pancreatic neoplasms most common was found minimal thickening of the duodenal wall, up to $8 \mathrm{~mm}$, the exact opposite of primary duodenal tumors. However, Stephens considers that a thickened duodenal wall, but without mentioning a minimum or maximum value, as unique radiological sign represents actually a pancreatic tumor with duodenal invasion [13].

Gourtsoyannis and Bays consider that in case of duodenal adenocarcinoma the duodenal wall will be thicker more than $15 \mathrm{~mm}$, but without referring to the neighborhood malignancies invading the duodenum [31].

Another possible reference point in defining the starting point of neoplasia, duodenum and pancreas, is the state of bile ducts. These changes were found only in $8 \%$ of primary duodenal tumors, and consisted in a moderate dilatation of choledoch, up to $1.5 \mathrm{~cm}$; this being obtained practically by the mass effect of the tumor on biliary duct and not by infiltration. In pancreatic neoplasia, in $29.5 \%$ of cases were seen variated changes of the biliary ducts. But if we relate this number of cases with changes of bile ducts only with cephalo-pancreatic neoplasms cases, the percentage is $50 \%$. This latest report is correct given that only cephalo-pancreatic neoplasms can directly invade the bile ducts. We did not refer to duct of Wirsung because the results have not revealed significant changes at this level. Regarding the CT characteristics of tumor we have not performed a detailed 
study on tumor enhancement, knowing that its intensity depends directly on the tumor blood supply, hence its aggressiveness, and in our study all tumors were adenocarcinomas, the real problem being represented by the starting point, namely from the duodenum or the pancreas.

\section{Conclusions}

If endoscopy cannot be performed, radio-imaging exams remain the only methods that can guide the starting point of a malignant tumor in duodenopancreatic region. It is important to know whether the tumor has duodenal or pancreatic origin for establish therapeutic strategy, the survival rate being different. This diagnosis is not of certainty, but has a quite high accuracy. The presence of lacunas, possibly with ulcers, localized on the third or fourth portion of the duodenum, directs the diagnosis towards a primary duodenal tumor. Instead, the existence of a lacuna with malignant character and dimensions between 2 and $4 \mathrm{~cm}$, localized on the descending duodenum is most likely a pancreatic neoplasia invading the duodenum. If a malignant lacuna, regardless the size or its location has polycyclic contours the diagnosis will be of primary duodenal tumor.

Malignant stenoses, accompanied by ulceration, and having more than $2 \mathrm{~cm}$ in size, conduct the diagnosis toward of a pancreatic tumor invading the duodenum, indifferent of its location. A tumor mass accompanied by a duodenal wall thickness over $10 \mathrm{~mm}$ is typical for a primary duodenal tumor, while a duodenal wall thickness less than $8 \mathrm{~mm}$ favor the diagnosis of pancreatic tumor invading the duodenum. The existence of changes in biliary ducts in case of tumors affecting the descending duodenum the diagnosis is almost certain of a cephalo-pancreatic tumor invading the duodenum.

\section{Acknowledgments}

All authors of this research paper have directly participated in the planning, execution, or analysis of this study, and also all authors of this paper have read and approved the final version submitted.

\section{References}

1. Jiang QL, Huang XH, Zhang JW, Zhang SS, Wang CF. Evaluation of disease free survival after radical resection for primary duodenal adenocarcinoma. Zhonghua Yi Xue Za Zhi. 2016;96(42):3393-3397. doi: 10.3760/cma.j.issn.0376-2491.2016.42.008.

2. Shamali A, McCrudden R, Bhandari P, Shek F, Barnett E, Bateman A, et al. Pancreaticoduodenectomy for nonampullary duodenal lesions: indications and results. Eur J Gastroenterol Hepatol. 2016;28(12):1388-1393.

3. Tang K, Lu W, Qin W, Wu Y. Neoadjuvant therapy for patients with borderline resectable pancreatic cancer: A systematic review and meta-analysis of response and resection percentages. Pancreatology. 2016;16(1):28-37. doi: 10.1016/j.pan.2015.11.007

4. Bergquist JR, Shubert CR, Ubl DS, Thiels CA, Kendrick ML, Truty MJ, et al. Risk by indication for pancreaticoduodenectomy in patients 80 years and older: a study from the American College of Surgeons National Surgical Quality Improvement Program. HPB (Oxford). 2016;18(11):900-907. doi: 10.1016/j.hpb.2016.07.012
5. Bakaeen F, Murr MM, Sarr MG, Thompson GB, Farnell MB, Nagorney $\mathrm{DM}$, et al. What prognostic factors are important in duodenal adenocarcinoma? Arch Surg. 2000;135(6):635-641.

6. Tocchi A, Mazzoni G, Puma F, Miccini M, Cassini D, Bettelli E, et al. Adenocarcinoma of the third and fourth portions of the duodenum: Results of surgical treatment. Arch Surg. 2003;138(1):80-85.

7. Suh CH, Tirumani SH, Shinagare AB, Kim KW, Rosenthal MH, Ramaiyaet $\mathrm{NH}$, et al. Diagnosis and management of duodenal adenocarcinomas: a comprehensive review for the radiologist. Abdom Imaging. 2015;40(5):1110-1120.

8. Darrah ER, Nolan DJ. Radiology of the duodenum. Hosp Med. 1999;60(1):10-8.

9. Galván-Salazar HR, Soriano-Hernández AD, Montes-Galindo DA Espíritu GC, Guzman-Esquivel J, Rodríguez-Sánchez IP, et al. Preclinical trial on the use of doxycycline for the treatment of adenocarcinoma of the duodenum. Mol Clin Oncol. 2016;5(5):657-659.

10. Manier J. Duodenal tumors. In: Haubrich WS, Schaffner F, Berk JE, editors. Bockus gastroenterology. 5th edition. Philadelphia: Saunders. 1994;875-881.

11. Kasper DL, Braunwald E, Hauser S, Longo D, Jameson JL, Fauci AS. Harrison's Principles of Internal Medicine, 16th edition McGraw-Hill Medical Publishing Division. 2005.

12. Lucas AL, Malvezzi M, Carioli G, Negri E, La Vecchia C, Boffetta P, et al. Global Trends in Pancreatic Cancer Mortality From 1980 Through 2013 and Predictions for 2017. Clin Gastroenterol Hepatol. 2016;14(10):1452-1462. doi: 10.1016/j.cgh.2016.05.034

13. Stephens DH. Adenocarcinoma of the Pancreas: Diagnosis and Staging. In: Freeny PC, Stevenson GW, eds. Margulis and Burhenne's alimentary tract radiology. 5th ed. St. Louis, Mo: Mosby-Year Book. $1994 ; 1107-1126$

14. Yamaguchi K, Enjoji M, Tsuneyoshi M. Pancreatoduodenal carcinoma: a clinicopathologic study of 304 patients and immunohistochemical observation for CEA and CA19-9. J Surg Oncol. 1991;47(3):148-154. DOI: $10.1002 /$ jso.2930470303

15. Sobin LH, Wittekind Ch . TNM classification of malignant tumours. 6th editon. Wiley-Liss. 2002;93-96.

16. Wong JC, Raman S. Surgical resectability of pancreatic adenocarcinoma: CTA. Abdom Imaging. 2010;35(4):471-480. doi: 10.1007/s00261009-9539-2

17.Chang ST, Jeffrey RB, Patel BN, DiMaio MA, Rosenberg J, Willmann JK, et al. Preoperative Multidetector CT Diagnosis of Extrapancreatic Perineural or Duodenal Invasion Is Associated with Reduced Postoperative Survival after Pancreaticoduodenectomy for Pancreatic Adenocarcinoma: Preliminary Experience and Implications for Patient Care. Radiology. 2016;281(3):816-825.

18. Liszka L, Mrowiec S, Kuśnierz K, Kajor M. Standardized grossing protocol is useful for the pathology reporting of malignant neoplasms other than adenocarcinomas treated with pancreaticoduodenectomy. Histol Histopathol. 2016;32(2):177-192.

19. Fu T, Sharmab A, Xie F, Liu Y, Li K, Wan W, et al. Methylation of MGMT Is Associated with Poor Prognosis in Patients with Stage III Duodenal Adenocarcinoma. PLoS One. 2016;11(9):e0162929.

20. Mouaqit O, Ktaibi R, Ktaibi A, Mounim M, El malki HOEl, Mohsine R, et al. A duodenal stromal tumor mimicking a pancreatic head tumor: one case report and literature review. Eur Surg. 2013;45(1):40-43. 
21. You HS, Hong JW, Yun EY, Kim JJ, Lee JM, Lee SS, et al. Primary Nonampullary Duodenal Adenocarcinoma: A Single-center Experience for 15 Years. Korean J Gastroenterol. 2015;66(4):194-201. doi: 10.4166/ kjg.2015.66.4.194

22. Maglinte DD, Lappas JC, Sandrasegaran K. Malignant tumors of the small-bowel. Gore R, Levine M (eds). Textbook of gastrointestinal radiology. 3rd edn Philadelphia, PA. Saunders Elsevier. 2008;853869.

23. Nolan DJ. Secondary Neoplasms, Chapter VI. In: Imaging of Small Intestinal Tumours. Elsevier. 1997;193-211.

24. Ferrucci JT. The Postbulbar Duodenum. In Taveras JM, Ferrucci JT (eds). Radiology. Philadelphia. Lippincott. Volume IV, Chapter 25. 1998

25. Helmberger TK, Ros LH, Baretton G, Reiser MF, Mergo PJ, Ros PR. Solid pancreatic lesions. Eur. Radiol. 1999;9(2):197-207.

26. Bosse G, Neely JA. Roentgenologic findings in primary malignant tumors of the duodenum. Report of 27 cases. Am J Roentgenol Radium Ther Nucl Med.1969;107(1):111-118.

27. Moss AA. Computed tomography in the staging of gastrointestinal carcinoma. Radiol Clin North Am. 1982;20(4):761-780.

28. Kasum'ian SA, Alibegov RA, Snytko NP. The surgical treatment of chronic duodenal obstruction in combination with chronic pancreatitis and tumors of the pancreaticoduodenal area. Vestn Khir Im I I Grek. 1997;156(4):42-45.

29. Bratu AM, Cristian D. Tumori duodenale - Consideratii imagistice si endoscopice. Bucuresti Ed. Universitara Carol Davila. 2014.

30. Loze S, Bercovici D, Masson B. Tumors of the digestive muscle. Diagnosis and treatment apropos of 10 cases. J Chir (Paris). 1994.131(11):496-500

31. Gourtsoyiannis NC, Ros PR. Primary Tumors of the Small Intestine. In: Gourtsoyiannis NC, Ros PR. Radiologic-Pathologic Correlations from Head to Toe: understanding the manifestations of disease. Berlin; New York. Springer. 2005.pp. 273-289. 